\title{
Social Upliftment as a Result of Green Space Provision in Rural Communities
}

\author{
Nicolene de Jong \\ Unit for Environmental Sciences and Management, North-West University, Potchefstroom, South Africa
}

\section{Email address:}

nicolenedejong@gmail.com

\section{To cite this article:}

Nicolene de Jong. Social Upliftment as a Result of Green Space Provision in Rural Communities. Agriculture, Forestry and Fisheries. Special Issue: Planning for Sustainable Communities: Green-Spaces in Rural Areas. Vol. 4, No. 4-1, 2015, pp. 14-20.

doi: $10.11648 /$ j.aff.s.2015040401.13

\begin{abstract}
Rural communities, especially those within the South African context, are faced with daily challenges - most of which are associated with a lack of basic social provisions, needs and spaces. This paper introduces the concept of green space planning as an alternative planning approach to address these social challenges within rural South African communities. It provides a comparative study between social challenges experienced in South Africa and the benefits provided by green spaces; introducing green space provision as an alternative planning method to address social challenges, especially those prevalent in rural South African communities. By providing successful and sufficient green spaces, numerous rural challenges are addressed and an overall upliftment of the communities' mental and physical well-being, social inclusion and quality of life is established.
\end{abstract}

Keywords: Social, Green Space, Rural, South Africa, Social Challenges

\section{Introduction}

Rural communities, especially within the South African reality, are widely defined as, and associated with concepts such as 'social backlog'; 'previously disadvantaged'; 'unsafe'; 'socially challenging'; etc.

Rural communities and the development thereof continue to be one of the main priorities within frameworks and constitutions guiding the economic and social development of (especially developing) countries. Reference [1] substantiates this statement by referring to the pervasiveness of poverty and poor delivery of basic services in rural areas as a primary constraint regarding a country's development efforts.

Therefore planning for rural communities and identifying or creating new approaches to rural development should receive a great deal of attention, as this is the core of addressing government's commitment to eradicate poverty [2] in a pro-active attempt at economic restitution and social upliftment.

Government is struggling to deal with rural challenges and related social issues (especially that of safety and security) and numerous strategies were formerly discussed and drawn up (for example the Rural Safety Summit which took place on 10 October 1998 aimed at achieving consensus regarding issues of rural insecurity; as well as crime prevention strategies as defined by the SAPS White Paper on Safety and Security (1998).) However, very little (if any) in-depth research on the possibility of upgrading public spaces into lively green places as solution has been done.

The failure of previous rural development projects implemented during the last three decades [1] leads to the consideration of different approaches that will focus and increase the relatively low development levels in the rural areas of South Africa [3] through interventions that support and enhance livelihood such as sound rural-development planning policies and programmes [3] that are oriented towards the provision of basic needs, the development of human resources and a growing economy in order to generate sustainable livelihoods [2].

In response to abovementioned necessities and social backlogs, numerous (primarily international) approaches have been implemented towards the creation and promotion of safe green spaces in an attempt to provide social benefits by promoting community integration [4]. These 'green spaces' provide more depth and meaning to a community than merely being a natural surface [4] between buildings [5], but fulfil a whole range of functions such as health functions, amenity and social functions as well as ecological functions [6]. It provides a unique platform for community integration [4] that can potentially influence the physical and mental well-being 
of community members [4] and contribute to their overall quality of life [6]. These green space benefits can be directly associated with and implemented as planning approaches to enhance the rural reality in South Africa and subsequently provide quality and sustainable rural communities.

This paper establishes a link between literature and practical rural issues by providing insight into the current reality of rural communities in South Africa as well as providing a defining background into green spaces and green space benefits. In creating public green spaces for rural communities, issues of safety, inequality, sociability and community coherence are addressed. Through the correct planning initiatives consequently drawn up, overall quality of life of those living in rural communities can be improved, decreasing the social challenges experienced and promoting sustainable rural communities.

\section{Rural Social Challenges: South African Communities as Case Study}

As mentioned in the introductory paragraph, South Africa as a developing country faces numerous challenges at a continuously increasing rate, especially regarding economic degrading and social backlog [7]. These economic challenges have a direct impact on the social development and overall quality of life of individuals living and working in South Africa, with an enhanced social degrading experienced in rural South Africa - hence the continuous existence of 'rural social challenges' [1].

\subsection{Background to the Correlation between 'Rural' and 'Social Challenges'}

When discussing a complex concept such as "rural", location and the delineation of such an area is of utmost importance. For the purposes of this paper it is necessary to define and comprehend "rural" specifically within a South African context.

The complexity of "rural" is substantiated by the broad spectrum of definitions and descriptions found globally on what "rural" means and what it encompasses. In South Africa, a 'rural community' is commonly perceived differently compared to other countries where the term usually demonstrates or refers to the density of a population and the dependence on manual labour [2]. Another perception of 'rural' is summarized in the LDCE [8] as a "happening in or relating to the countryside, not the city". The European definition of 'rural' refers to any agricultural land and/or areas [2].

When abiding to the first perception of 'rural' as defined by the DRDLR [2] the term "rural" would have defined the whole of South Africa (all-inclusive) up until 1995 (referring to the outcomes of censuses and official surveys) [2] and the other perceptions would not encapsulate the unique and detailed composition of 'rural' areas as found in South Africa.

In reaction to these deficit definitions regarding 'rural' in the South African context, the Rural Development Framework of South Africa that was originated in 1997, defined 'rural' as "... the sparsely populated areas in which people farm or depend on natural resources, including villages and small towns that are dispersed through these areas" [2].

The relevance and importance of the social dimension of planning as a key component of sustainable development was ignored for many years where focus was mainly directed at environmental issues and the integration of the environmental and economic dimension. Due to various developments and advancements the social dimension was recently included as an equally relevant and influential dimension as the aforementioned [9]. The ISRDS [1] further emphasize the increasing accountability of the 'social'component of planning especially regarding its contribution to development and development practices. Scoones [10] provides a sound basis when highlighting the importance of society and people as the anchor of social development - especially their local needs and cultural contexts.

Philips [11] expands 'social' and the irreplaceable importance of people and the society within the 'social'-persona by including various aspects such as safety, culture, housing, labour and community relations. The DRDLR [1] expands this defining list by including social services like food and water, shelter, energy, health and education, and transport and communication services.

In order to present a platform when addressing something as broad and unlimited as 'social', the mixed definition will be accepted conditionally, as defined by Henslin [12]. He defines a social problem (or for the purpose of this paper a social challenge) as "an aspect of society that people are concerned about and would like changed." This refers to a social challenge as something (an aspect, happening or circumstance for example) within the community that one can measure or experience. Simultaneous to this, another key element regarding social problems is that of a subjective concern, which refers to a concern that a number of people have regarding the previously-mentioned condition. Overall, anything people-oriented or contributing to human experience (positively or negatively) can be included as part of 'social' and any happening or circumstance disturbing or disadvantaging 'social' and all its aforementioned aspects can be regarded as 'social challenges'.

The importance of people and the human aspect of social can indeed be seen as another possibility for the eruption of more social challenges. According to Veenhoven and Ehrhardt's [13] theory of liveability, the challenge of social inequality because of differences in dispersion across nations might occur, providing sufficient substance for this paper's focus on enhanced social challenges (as defined and discussed above) as experienced in rural communities - even more that of South Africa.

\subsection{Social Challenges Experienced in South African Rural Communities}

In the light of the background given in the previous section regarding the defining of 'rural' and 'social challenges', it is evident that the challenges as experienced and identified in the 
South African context are primarily rooted in the lack of social development present - a lack much heftier experienced in rural communities. The ISRDS [1] substantiates this statement by referring to the pervasiveness of poverty and poor delivery of basic services in rural areas as a primary constraint regarding a country's development efforts.

In South Africa, rural development is an even more predominant challenge as it is estimated that half of South Africa's population lives in rural areas [14] and that an astonishing three quarters of this country's people living below the poverty line or MLL (minimum living level) live in these rural areas [2].

This serves as statistical proof and support for the interceding statement of this article that associates characteristics such as 'backlog', 'social challenges' and 'disadvantaged' with rural communities and (based on above) especially with regards to South African rural communities.

In support to above, the following table provides a concise and conducive summary of three researched rural communities and the primary challenges identified within these communities.

With reference to former sections of this article in which the concepts of 'social' and 'social challenges' were defined, it can justifiably be derived that the majority of the challenges as identified, coincide with concepts included in the broad spectrum of 'social'. As 'social challenges' were formerly described as any happening or circumstances disturbing the social nature (i.e. people-oriented aspects) of communities, it proves evident that above can be regarded as the blueprint for rural social challenges within a South African context.

\section{Green Space Planning}

\subsection{Defining and Understanding the Context of Green Spaces}

A green space is diversely defined. Barbosa et al. [4] defines a public green space as every parcel of land classified as a natural surface, judged to be publicly accessible. 'Natural surface' means the green space should be predominantly natural (i.e. earth, water and living things) with a sense of quality and the presence of several maintained facilities [16], therefore introducing green spaces as the 'glue' between buildings [5].

These green spaces fulfil a whole range of functions such as health functions, amenity and social functions as well as ecological functions [6]. The execution of these functions lies within the inclusion of certain aspects or areas.

Public green spaces can provide social benefits by promoting community integration in a way that private gardens cannot, since social interactions in gardens are focused around a private social network [4]. They also provide the primary contact with biodiversity and the 'natural' environment (refer to previous definition of natural surfaces as defined by Shackleton and Blair [16]) for many people and may therefore influence the physical and mental well-being of those people [4] as well as contribute to their overall quality of life [6]. The direct managerial role of government is established in Young [17]'s definition of green spaces as "...publicly managed natural resource assets... including street trees, parks, 'natural areas'...".

For the purpose of this paper, green spaces will mean (as compiled and summarized from above) safe and maintained parcels of land that remains predominantly natural, dispersed throughout a community with sustainable sense of quality and the presence of a variety of maintained functions and social facilities for residents.

The following citations summarize the potential benefits and/or influences that may emerge with the successful provision of the former combined definition of 'green space' (i.e. successful provision implies all aspects included in the definition should be adhered to such as safety, natural environment, maintained, quality, variety, etc.):

Shifting the paradigm of spatial segregation into multifunctional landscapes [16] wherein 'quality' regarding these spaces are linked to the 'value' associated with spaces by recognizing the need of these spaces to reflect the changing social, economic and environmental conditions;

Economic benefits like the enhancement and provision of economic prosperity that becomes evident when preserving and enhancing natural ecosystems (i.e. green spaces) [18];

It has a very particular value and plays a unique role in the sustainability and liveability of towns and cities, the provision of which requires appropriate planning approaches, implementation strategies and financial resources [16];

Green spaces address and therefore contribute (in many ways) to sustainable development beyond merely providing recreational value [5] but rather making a valuable contribution across the spectrum of social, environmental and economic benefits [19];

The importance and value of green spaces to the people is further emphasized in the study of Shackleton and Blair [16], wherein a survey resulted in the average of $93 \%$ of respondents stating that PGS (public green spaces) are important (substantiated by Ward et al. [20] with 99\% of surveyors regarding urban green spaces as important). The reason for their decision and therefore the summary of values associated with green spaces in communities include amongst others [16, 20]:

Recreation and relaxation;

Provision of jobs (creation of such spaces need to be maintained);

Environmental benefits;

Attraction of tourism (also contributes to the potential provision of jobs);

Promotion of human well-being;

Appreciation and exercise (health)

Enhancing quality of life;

Escapism and breathing space;

Preservation for future generations (i.e. sustainability);

Events, concerts and alternative displays;

Education and research; and

Spiritual and moral functions.

Despite these valuable contributions of green spaces, the 
Department of Transport, Local Government and the Regions (DTLR) [21] stated that these invaluable resources are often neglected, resulting in a loss of potential and potential benefits. Therefore, in order to enhance the potential and benefits that the green spaces can provide, it is crucial to focus on the quality of the green spaces, and the management of these spaces within any given community.

\subsection{Green Spaces and Associated Challenges and/or Deficiencies: South African Context}

The challenges in planning and maintaining urban public green spaces in towns in the developing world such as South
Africa differ remarkably from those of the developed world as discussed in the previous section on international approaches [16]. Developing countries experience high levels of urbanisation and population growth prohibiting urban planning agencies to keep up and contributing to green space planning in areas which are rather being targeted for land invasion [22]. South Africa, being a developing country, therefore provides an interesting opportunity to examine the distribution of public green space in a developing country in relation to wealth attributes - wealth being correlated to public green space attributes [22].

Table 1. Challenges experienced in various South African rural communities.

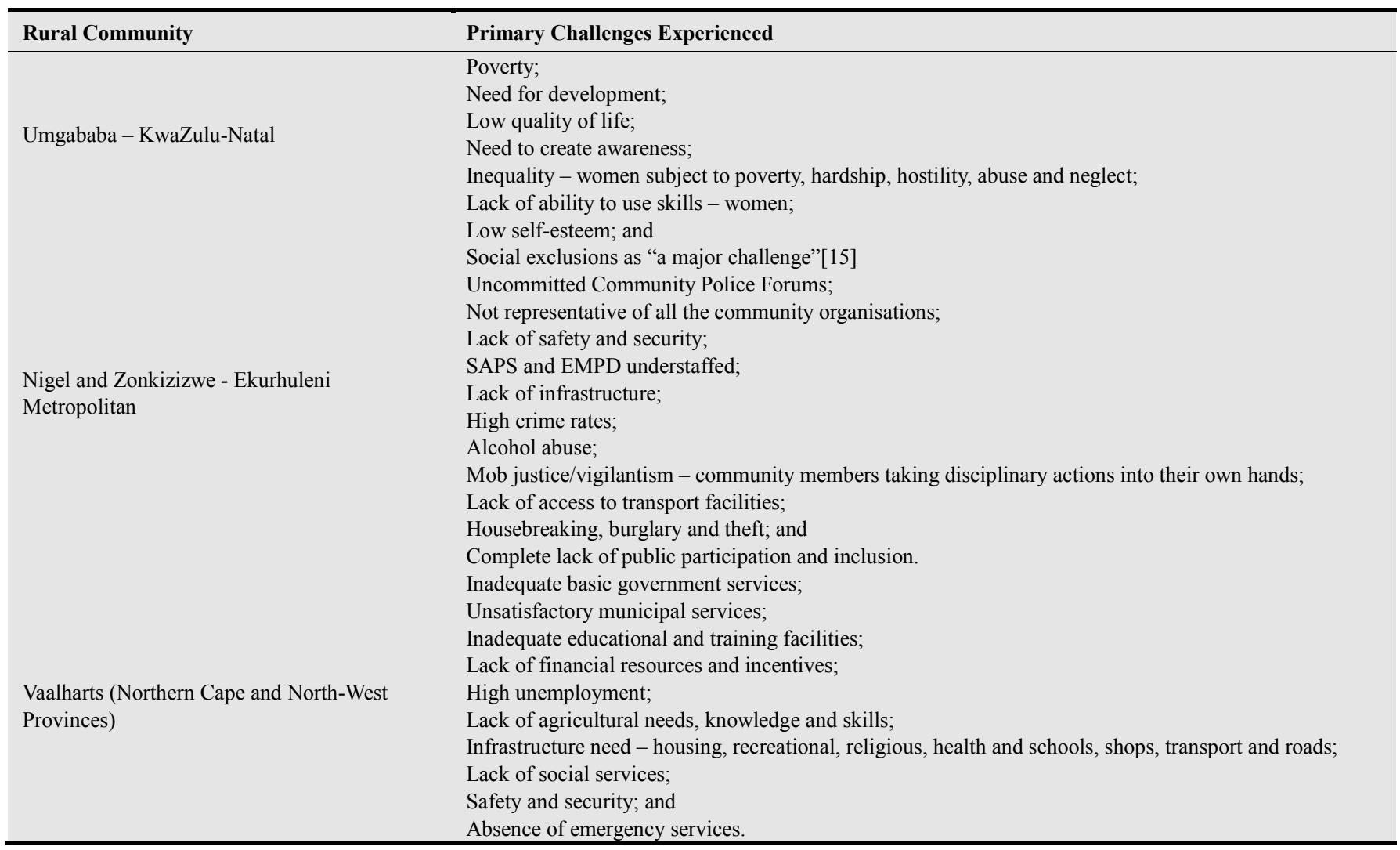

The majority of residents (as responded in a survey conducted in two small towns in the Eastern Cape Province of South Africa) agreed that there was insufficient public green space (PGS) in their respective towns and suburbs and that the local municipality did not do enough in providing efficient and sufficient PGS or maintaining existing spaces [16]. Ward et al. [20] agree with $55 \%$ of respondents stating that there is insufficient green space planning within urban areas.

Even though residents experience a high level of dissatisfaction with the amount and condition of current PGS and insufficient municipal commitment and funds to adequately maintain these PGS, there still exists a high level of willingness amongst residents to get involved (either through a commitment of time or funds) [16]. The importance of understanding residents' needs and attitudes is therefore important in ensuring that planning and management objectives are grounded in local needs and desires regarding PGS [16] in order to create efficient green spaces they want and would visit.

Improving attributes such as accessibility [4], proximity [16] and safety [4] contribute to the attraction of green spaces, increasing the frequency and duration of visits. By creating public green spaces which are fully maintained and cared for, the feeling of being unsafe is eliminated, contributing to the overall value and success of these public green spaces [16] which enhances the values not only of the green spaces themselves, but the whole of the community in which they are successfully provided.

The case study areas were selected at random based on the relevant data available for the purposes of this paper. The selected case studies are also representative of a broad spectrum of the South African regions including a case study 
area located in KwaZulu-Natal, Ekurhuleni/Gauteng, and the North West/Northern Cape Provinces, therefore successfully representing a variety of culture groups, differently performing economic areas and covering a large area of the country's extent.

The table merely concludes a small sample of challenges faced in South African rural communities, but the continuous similarities proves that it can serve as a sufficient representative of other rural communities in South Africa. A collective summary of the primary challenges experienced i.e. challenges regarded as "social challenges" based on former definitions as listed above can be regarded as basic human needs; sufficient social services and facilities; need for infrastructure (housing, shops, roads, transport); lack of safe and secure spaces and viable security services; inequality; social exclusion and associated decrease in self-esteem and self-worth; poverty; unemployment; overall low quality of life; and unmaintained (unsafe) spaces, areas and infrastructure.

It deems inevitable therefore that planning for rural communities and identifying or creating new approaches to rural development should receive a great deal of attention, as this is the core of addressing government's commitment to eradicate poverty [2] and addressing various other social challenges reported above. A sustainable and viable option for such "...new approaches to rural development" proves to be that of green space planning and provision and will be substantiated in sections to follow.

\section{Rural Communities and the Social Benefit of Green Space Planning}

\section{Role of Green Spaces in Enhancing Social Benefits}

Swanwick et al. [19] refer to the social benefits of urban green space planning as having both "....an existence value, because people know it is there, and a use value for a wide range of different activities." This is further supported by Barbosa et al. [4] referring to green space planning as providing purported social benefits by bringing diverse communities together and promoting interactions between people from different socio-economic and ethnic groups.

In collaborating the challenges of South African rural communities as listed and summarized in Table 1 and reviewing them in the light of the benefits associated with providing sufficient and successful green spaces (refer to section 3.1. of this article as to what is regarded as "successful provision of green spaces"), the indubitable positive outcome of providing green spaces in rural communities as a planning approach to potentially address rural social challenges, is evident:

Table 2. Correlation between rural social challenges and green space benefits.

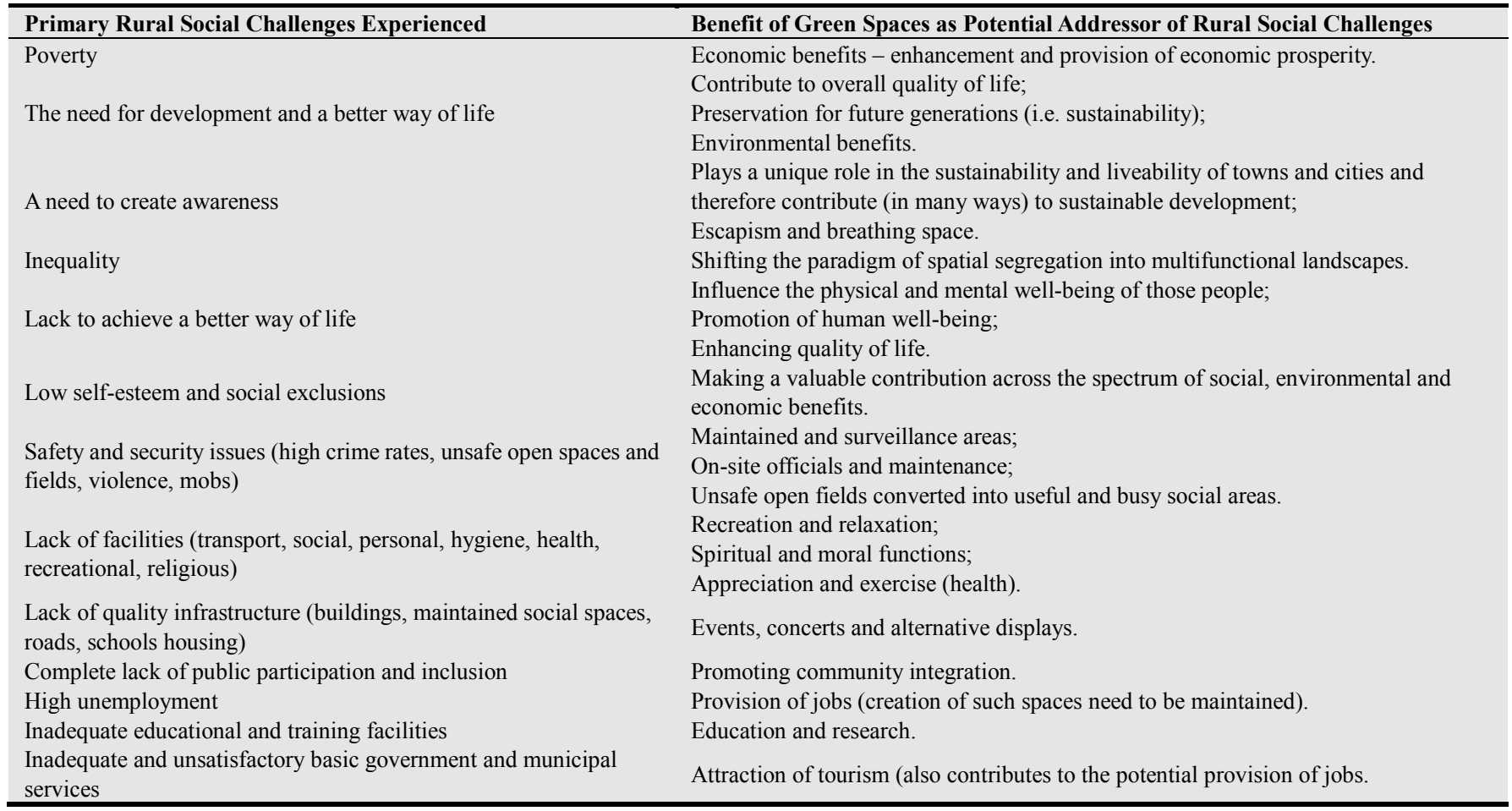

The table above represents various rural challenges and social benefits of green spaces as found in the relative former sections. This table therefore provides a strategic representation to proof the undeniable similarities between the primary challenges and struggles experienced in rural communities and the social benefits provided by creating successful green spaces within any given community.

\section{Conclusion}

When providing sufficient areas of green space that are also accessible, these PGS (public green spaces) will promote 
connection with the places in which people live and work therefore eliminating long travel distances and improving accessibility, providing relative easy means for recreation, exercise, relaxation and other human health and well-being related challenges. This is reflected in the perceptions they form about green spaces and will also influence their maintaining and respecting the use of these public green spaces [16], therefore motivating them to personally get involved and contribute in such a manner that they feel a sense of ownership and inclusion within their community. This will subsequently fuel their self-worth and indirectly contribute to the state of their mental and physical well-being, thus increasing the level of the quality of life they currently experience - i.e. providing an overall sense of social upliftment due to the simultaneous addressing of various previously experienced social challenges.

In subsection 2.1 the concepts of both 'rural' and 'social challenges' were elaborated through the inclusion of various definitions, contexts and citations. In all of the above expressions the direct relation between rural communities (especially in South Africa) and the presence of persistent social challenges is established.

This relevance and applicability in South African context is substantiated in subsection 2.2 and listed in Table 1 where various South African communities and their predetermined social challenges are included.

As introduction to the probability and applicability of green space planning as addressor of rural social challenges, the context of "successful PGS (public green spaces)" is defined in subsection 3.1.

The inverse correlation between the rural social challenges of the South African case study communities summarized in Table 1 and the benefits of providing green spaces in communities are drawn in section 3.2.

Section 4 emphasizes the probability of addressing aforementioned rural social challenges by providing these successful green spaces. Table 2 serves as a supportive summary, representing a concise listing of the primary social challenges formerly identified in the rural case study areas (left column). The column to the right represents some of the benefits of providing green spaces as derived from the in-depth discussion in Section 3. The green space benefits (right column) are arranged next to the corresponding social challenge (left column) that it can potentially address and/or uplift.

Therefore Table 2 provides visually presented proof that green spaces can potentially provide upliftment for each identified rural social challenge. This leads to an inevitable decrease in social challenges, culminating in an overall social upliftment for any given rural South African community.

\section{References}

[1] Department of Rural Development and Land Reform see South Africa (1). Department of Rural Development and Land Reform.
[2] South Africa (1). Department of Rural Development and Land Reform, Integrated Sustainable Rural Development Strategy (ISRDS), 2000, Pretoria.

[3] Department of Rural Development and Land Reform see South Africa (2). Department of Rural Development and Land Reform.

[4] South Africa (2). Department of Rural Development and Land Reform, Rural Development Framework (RDF). 1997, Pretoria.

[5] NSDP see South Africa (3).

[6] South Africa (3), National Spatial Development Perspective (NSDP), 2006, The Presidency, RSA.

[7] O. Barbosa, J.A. Tratalos, P.R. Armsworth, R.G. Davies, R.A. Fuller, P. Johnson \& K.J. Gaston, Who benefits from access to green space? A case study from Sheffield, UK, 2007, Landscape and Urban Planning, 83 (2007): 187-195.

[8] O. Wilson \& O. Hughes, Urban Green Space Policy and Discourse in England under New Labour from 1997 to 2010, 2011, Planning Practice \& Research, 26(2):207-228.

[9] E. Lange, S. Hehl-Lange \& M.J. Brewer, Scenario-visualization for the assessment of perceived green space qualities at the urban-rural fringe, 2007, Journal of Environmental Management, 89(2008):245-256.

[10] P. McGroarty, South Africa's Economic Growth Continues to Decline., 2014 , http://www.wsj.com/articles/south-africas-economic-growth-co ntinues-to-decline-1416913563 Date of access: 30 March 2015.

[11] LDCE (Longman Dictionary of Contemporary English), Harlow, England: Pearson Education Limited, 2003, 2272p.

[12] I. Mulalic, Embedding social dimensions into economic and environmental accounting and indicator systems: Some aspects to consider. Copenhagen, Denmark: Statistics Denmark, 2004.

[13] I. Scoones, Livelihoods perspectives and rural development. Journal of Peasant Studies, 2009, 36(1):1-26.

[14] Philips, Liveable Cities: Challenges and opportunities for policymakers, A report from the Economist Intelligence Unit. London: The Economist Intelligence Unit, 2010.

[15] J.M. Henslin, Social Problems, 2003, $\mathrm{http}: / /$ wps.prenhall.com/hss henslin socprob 6/0,6624,49456 3-,00.html Date of access: 3 March 2013.

[16] R. Veenhoven \& J. Ehrhardt, The cross-national pattern of happiness: Test of predictions implied in three theories of happiness. Social Indicators Research, 1995, 34:33-68.

[17] C. Campbell, Y. Nair, S. Maimane \& Z. Sibiya, Supporting people with AIDS and their carers in rural South Africa: Possibilities and challenges, 2008, http://eprints.lse.ac.uk/5471/ Date of access: 28 Feb. 2013.

[18] M. Gopaul, The significance of rural areas in South Africa for tourism development through community participation with special reference to Umgababa, a rural area located in the province of KwaZulu-Natal. Pretoria: University of South Africa, 2006. (Dissertation - Master of Arts).

[19] C.M. Shackleton \& A. Blair, Perceptions and use of public green space is influenced by its relative abundance in two small towns in South Africa. Landscape and urban Planning, 2013, 113(2013):104-112. 
[20] R.F. Young, Managing municipal green space for ecosystem services, Urban Forestry \& Urban Greening, 2010, 9(2010):313-321.

[21] J.O. Odindi \& P. Mhangara, Green Spaces Trends in the City of Port Elizabeth from 1990 to 2000 using Remote Sensing. International Journal of Environmental Research, 2012, 6(3):653-662.

[22] C. Swanwick, N. Dunnet \& H. Woolley, Nature, Role and Value of Green Space in Towns and Cities: An Overview. Built Environment, 2003, 29(2):94-106.
[23] C.D. Ward, C.M. Parker \& C.M. Shackleton, The use and appreciation of botanical gardens as urban green spaces in South Africa. Urban Forestry and Urban Greening, 2009, 9(2010): 49-55.

[24] Department for Transport, Local Government and the Regions (DTLR), Green Spaces, Better Places: Final Report of the Urban Green Spaces Taskforce. London: TSO, 2002.

[25] M.M. McConnachie \& C.M. Shackleton, Public green space inequality in small towns in South Africa. Habitat International, 2009, 34(2010):244-248. 